Research Article

\title{
Dynamic Crack Propagation and Fracture Behavior of Pre-cracked Specimens under Impact Loading by Split Hopkinson Pressure Bar
}

\author{
Shijun Zhao $\mathbb{D}^{1,2}$ and Qing Zhang $\mathbb{D}^{1}$ \\ ${ }^{1}$ College of Mechanics and Materials, Hohai University, Nanjing 211100, China \\ ${ }^{2}$ Department of Mechanical and Materials Engineering, University of Nebraska-Lincoln, Lincoln, NE 68588, USA
}

Correspondence should be addressed to Qing Zhang; lxzhangqing@hhu.edu.cn

Received 25 March 2019; Revised 7 May 2019; Accepted 20 May 2019; Published 23 June 2019

Guest Editor: Grzegorz Lesiuk

Copyright (c) 2019 Shijun Zhao and Qing Zhang. This is an open access article distributed under the Creative Commons Attribution License, which permits unrestricted use, distribution, and reproduction in any medium, provided the original work is properly cited.

\begin{abstract}
Deformation and fracture of brittle materials, especially crack propagation, have drawn wide attention in recent years. But dynamic crack propagation under impact loading was not well understood. In this paper, we experimentally tested Brazilian disk (BD) fine sandstone specimens containing pre-cracks under cyclic impact loading by the $\Phi 74 \mathrm{~mm}$ diameter split Hopkinson pressure bar (SHPB) test device. The pre-cracked specimens were named central straight through crack flattened Brazilian disk (CSCFBD). By using the low air-pressure loading conditions $(0.1 \mathrm{MPa}$, equal to the impact velocity of $3.76 \mathrm{~m} / \mathrm{s})$, a series of dynamic impact tests were detected successfully, and the effects of pre-cracks on dynamic properties were analyzed. Experimental results show that the multiple cracks mostly initiate at/or near the pre-crack tips and then propagate in different paths and directions varying by inclination angles, leading to the ultimate failure. Compared to static or quasi-static loading, dynamic crack propagation and fracture behavior are obviously different. Furthermore, we characterized the crack propagation paths, directions, and fracture patterns and discussed the influences of the pre-cracks during the breakage process. We concluded that the results obtained are significant in investigating the failure mechanism and mechanical properties of brittle materials under impact loading.
\end{abstract}

\section{Introduction}

Dynamic deformation and fracture of brittle materials are complex processes. Mining, tunnel excavation, and natural disasters such as landslides and earthquakes are all involved in the problems of dynamic damage. The failure of brittle materials is usually associated with crack propagation initiated from natural or artificial pre-existing defects. Moreover, the mechanical properties of brittle materials are closely related to external loading conditions, such as loading rate and load magnitude [1-3]. Rock is one of the most complex brittle materials containing different scale voids, cracks, and other defects, as shown in Figure 1, which are the main mechanical factors that affect the rock deformation and failure [4]. Crack growth and catastrophic failures initiated from pre-existing defects subjected to multiaxial loads are the main concerns for geotechnical engineers and designers of underground structures. The defects in rock can promote the initiation of new defects, which in turn may propagate and coalesce with other defects, and then can further decrease the strength of the rock mass [5-8]. The presence of pre-cracks may obviously reduce the fracture toughness, dynamic uniaxial compressive strength, and dynamic tensile strength and lead to fragmentation and multiple crack interactions, branching, and coalescence [9].

Due to the difficulties of in-situ tests, the laboratory experiment is an important and effective research method to investigate rock failure modes and fracture mechanisms. Over the past few decades, many experiments have been devoted to use semi-circular core in the three-point bending (SCB) specimen [10], Brazilian disk (BD) specimen with chevron flaws or other pre-existing flaws [11], radial cracked 


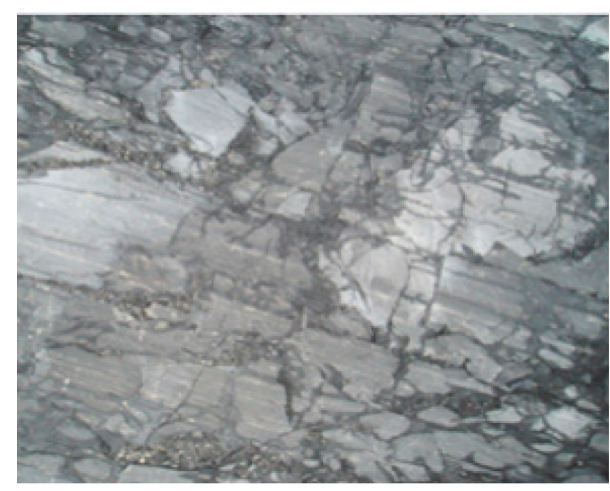

FIGURE 1: Schematic view of pre-existing defects in the natural rock mass [4].

ring (RCR) specimen [12], and modified ring (MR) specimen [13] to investigate fracture toughness and crack propagation. Note that, in previous studies, the fracture behavior and crack propagation of brittle materials were mainly investigated under static/quasi-static loading or used in intact specimens. Irwin et al. [14-16] divided the simple cracks into three types in the basic failure process: Mode I (the tension/opening mode) crack, Mode II (the sliding mode), and Mode III (the tearing mode) crack. In engineering, Mode I cracks are of prime importance. More complicated cracks can form from these simple cracks, called mixed-mode cracks. Many experimental studies have been conducted to explain the crack initiation, propagation, and coalescence in pre-cracked brittle materials under static or quasi-static loading [17-21]. The BD test is an effective way to study crack propagation and fracture behavior of brittle materials [22, 23]. Al-Shayea [24] studied crack propagation paths in pre-cracked limestone central straight though crack Brazilian disk (CSCBD) specimens loaded with diametrical compression, and they investigated the possibility of using outcrop specimens to estimate the fracture toughness behavior of the reservoir rock at in-situ conditions of temperature and confining pressure. Haeri et al. [25-27] used Portland Pozzolana Cement (PPC) experimentally and studied crack propagation and crack coalescence of $\mathrm{BD}$ pre-cracked and pre-holed specimens under quasi-static compressive and tensile loading. Aliha and Bahmani [28] investigated fracture toughness under mixedmode loading using different cylindrical and disc shapes for the brittle material. However, in deep strata, the damage and destruction of rock mass are often caused by dynamic even cyclic dynamic loading. None of these investigations listed above has ever captured the dynamic multiple crack propagation. In such cases, it is of great significance and essential to investigate the dynamic crack propagation and fracture patterns of rock in deep strata under impact/cyclic impact loading.

Various experiments devices have been used to explore a wide range of strain rates. Split Hopkinson pressure bar (SHPB) technique, which decouples cleverly the inertia effect in structures and strain rate effect in materials, has been widely used to characterize the dynamic performance of various engineering materials at high strain rate, such as rock [29-33], concrete [34-38], and ceramics [39, 40] at high strain rates $\left(10^{2} \sim 10^{4} \mathrm{~s}^{-1}\right)$. The strain rate sensitive behavior of brittle materials has been under investigation for several decades. The strain rate sensitivities are mainly measured by strength or the strains at the maximum stress $[41,42]$. In recent years, a variety of researchers have investigated and demonstrated the dynamic properties of natural or artificial brittle materials [43-47], and they found that the dynamic strength (including dynamic compressive strength and dynamic tensile strength) and impact toughness increases with strain rate and the strain rate sensitivity of brittle materials.

In this paper, we defined some central straight through crack flattened Brazilian disk (CSCFBD) specimens to investigate dynamic crack propagation and fracture patterns under impact loading by the SHPB device, and the term "pre-crack(s)" is used to describe the artificially created crack. The motivation for this work will focus on the following two points: (1) investigating the dynamic fracture patterns, multiple crack propagation paths, and directions in pre-cracked specimens; (2) characterizing and analyzing the crack types initiated from pre-cracks under cyclic impact loading. This paper is organized as follows: in Section 2, the preparation of tested CSCFBD specimens and experimental procedure are discussed. The SHPB experimental scheme is also introduced. In Section 3, we present the experimental results. We look at both the multiple crack propagation paths and directions. In Section 4, we discuss the experimental results and characterize the dynamic fracture patterns and failure modes. The conclusions concluded upon the foregoing results are given in Section 5.

\section{Preparation of Disk Specimens and Experimental Procedure}

Due to the crystalline and blocky structures, fine sandstone is widely used to investigate the fracture behavior and crack propagation of defected brittle materials. In this paper, we used fine sandstone to study the dynamic crack propagation under impact loading. The fine sandstone samples were excavated by geologic drilling from about 900-meter depth underground strata in Juye coalfield, whose Cenozoic formation is very thick. The average thickness of strata in the fourth system is $158.43 \mathrm{~m}$, and the average thickness of the upper tertiary strata is $497.01 \mathrm{~m}$. And the thickness of the new boundary layer is $530 \sim 720 \mathrm{~m}$, mainly composed of clay, sandy clay, sand, fine sand, and gravel. Main coal seam roof and floor sandstone thickness is $4.80 \sim 75.65 \mathrm{~m}$, mainly fine sandstone, local sandstone, and siltstone [4]. The precracked specimens' preparation and experimental procedures will be explained as follows.

2.1. Preparation of CSCFBD Specimens. For manufacturing CSCFBD specimens, the whole tests used six samples with each one cored into $30 \sim 50 \mathrm{~cm}$ long, diameter $D=62 \mathrm{~mm}$ cylindrical columns in the construction site. In order to avoid external environmental influence, the surface of the samples was wrapped in the multilayer food preservation film after removing from the formation. The specimens were cut into BD shapes with the size of $\Phi 62 \times 30 \mathrm{~mm}$. Three 
specimens with same pre-crack geometry were prepared to guarantee the reproducibility of these experimental tests, and a total number of 21 CSCFBD specimens were manufactured in this work. The physical and mechanical properties of the tested fine sandstone are listed in Table 1.

Various Brazilian tests were conducted on CSCFBD specimens containing a single crack with different inclination angles. These pre-cracks were created by the highspeed water jet cutting machine [4], as shown in Figure 2. Figure 3 shows pre-cracked specimens with different inclination angles and the crack inclination angle $\beta$ (the angle between the normal line of the pre-crack surface and the vertical direction of the impact load), $\beta=0^{\circ}, 15^{\circ}, 30^{\circ}, 45^{\circ}, 60^{\circ}$, $75^{\circ}$, and $90^{\circ}$. Figure 4 shows a schematic view of CSCFBD specimens. The pre-cracks length, $2 b$ ( $b$ is the half of precrack length), is equal to $10 \mathrm{~mm}$, and the crack width is $1 \mathrm{~mm}$. The radius and thickness of the CSCFBD specimen are $R=31 \mathrm{~mm}$ and $H=30 \mathrm{~mm}$. Crack length ratio is an important parameter for the pattern, trajectory, and the number of fractures; in this work, the ratio $b / R$ is 0.16 .

2.2. SHPB Experimental Procedure. In this work, the dynamic tests were taken in the structure laboratory of Hohai University, adopting $\Phi 74 \mathrm{~mm}$ diameter straight taper variable cross sections SHPB device. The $\Phi 74 \mathrm{~mm}$ diameter SHPB device mainly composes of the power system (which propelled by a gas gun), elastic bars (an incident bar, a transmitter bar, and an absorbing bar), a damper, energy absorbing setup, high dynamic strain indicator and data processing systems. The power system consists of an air compressor and pressure vessel. The impact velocity is measured by the light electric tachometer. Schematic of the SHPB test device is shown in Figure 5.

The SHPB device is based on the one-dimensional theory of elastic wave and uses Lagrangian coordinates to describe all the physical parameters. The control equations of waves in the bars are on the following assumptions. Onedimensional assumption: speed $v$ and the strain $\varepsilon$ are only the function of point $X$ and time $t$ and the assumption that the strain rate is independent. Assuming axial wave propagation and homogeneous stress distribution in the specimen, the resulting stress $\sigma_{\mathrm{s}}(t)$, strain $\varepsilon_{\mathrm{s}}(t)$, and strain rate $\dot{\varepsilon}(t)$ of the specimen are obtained by the following equation [48]:

$$
\begin{aligned}
& \sigma_{\mathrm{s}}(t)=\frac{S_{\mathrm{B}} E}{2 S_{\mathrm{S}}}\left[\varepsilon_{\mathrm{t}}(t)+\varepsilon_{\mathrm{r}}(t)+\varepsilon_{i}(t)\right], \\
& \dot{\varepsilon}_{\mathrm{S}}(t)=\frac{C_{0}}{L_{\mathrm{S}}}\left[\varepsilon_{\mathrm{t}}(t)+\varepsilon_{\mathrm{r}}(t)-\varepsilon_{i}(t)\right], \\
& \varepsilon_{\mathrm{t}}(t)=\frac{C_{0}}{L_{\mathrm{S}}} \int_{0}^{t}\left[\varepsilon_{\mathrm{t}}(t)+\varepsilon_{\mathrm{r}}(t)-\varepsilon_{i}(t)\right] d \tau,
\end{aligned}
$$

where $S_{\mathrm{B}}, E$, and $C_{0}$ are the cross-sectional area $\left(\mathrm{mm}^{2}\right)$, Young's modulus $(\mathrm{GPa})$, and the wave velocity $(\mathrm{km} / \mathrm{s})$ of the bar material and $L_{S}$ and $S_{s}$ are the length $(\mathrm{mm})$ and cross-sectional area $\left(\mathrm{mm}^{2}\right)$ of the specimen. $\varepsilon_{i}(t), \varepsilon_{\mathrm{r}}(t)$, and $\varepsilon_{\mathrm{t}}(t)$ are the strain singles in specimen. The diameter,
TABle 1: Physical and mechanical properties of the tested fine sandstone.

\begin{tabular}{lc}
\hline Properties & Value \\
\hline Young's modulus, $E(\mathrm{GPa})$ & 11.1 \\
Compressive strength, $\sigma_{\mathrm{c}}(\mathrm{MPa})$ & 84.1 \\
Brazilian tensile strength, $\sigma_{\mathrm{t}}(\mathrm{MPa})$ & 3.0 \\
Longitudinal wave velocity, $V_{\mathrm{P}}(\mathrm{m} / \mathrm{s})$ & 3526.4 \\
Porosity $(\%)$ & 8.3 \\
Poisson's ratio, $v$ & 0.33 \\
Density, $\rho\left(\mathrm{kg} / \mathrm{m}^{3}\right)$ & 2692 \\
\hline
\end{tabular}

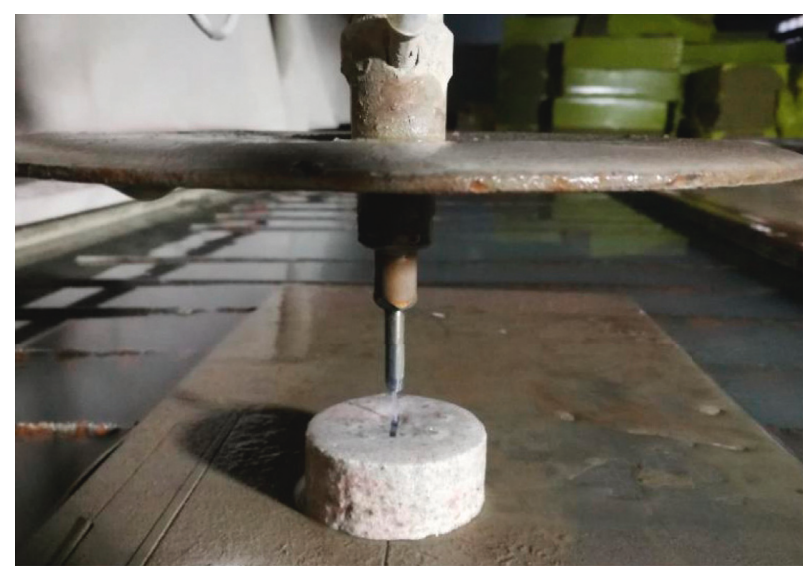

FIgURE 2: Pre-crack preparation in CSCFBD specimens using a water jet cutting machine [4].

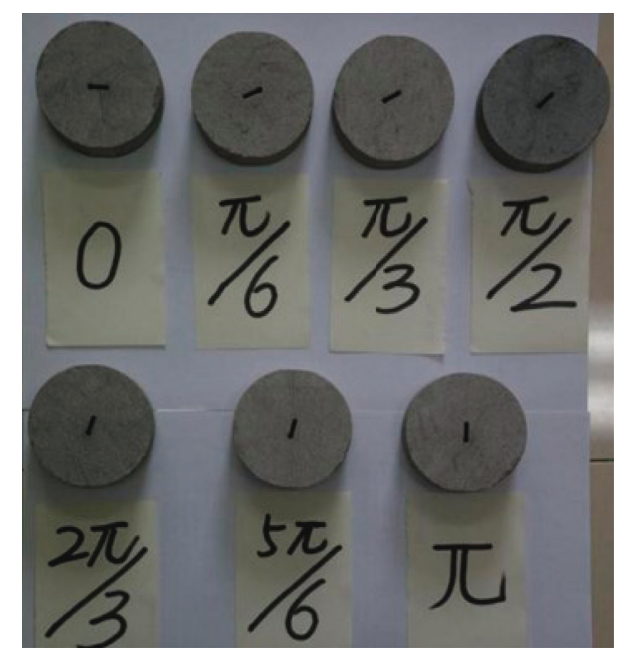

Figure 3: Schematic view of CSCFBD specimens with different inclination angles of pre-cracks.

Young's modulus, and density of the elastic bars are $74 \mathrm{~mm}$, $210 \mathrm{GPa}$, and $7850 \mathrm{~kg} / \mathrm{m}^{3}$, respectively.

In fact, during the experimental tests by $\mathrm{BD}$ specimens, the cracks of samples are first produced by the center and then expanded along the radial direction. Wang et al. [49] presented that if the samples between two planes parallel to the plane of the degree of smoothness and not less than $0.05 \mathrm{~mm}$, then they can ensure that the fracture initiated from the specimen center. The loading areas corresponding 


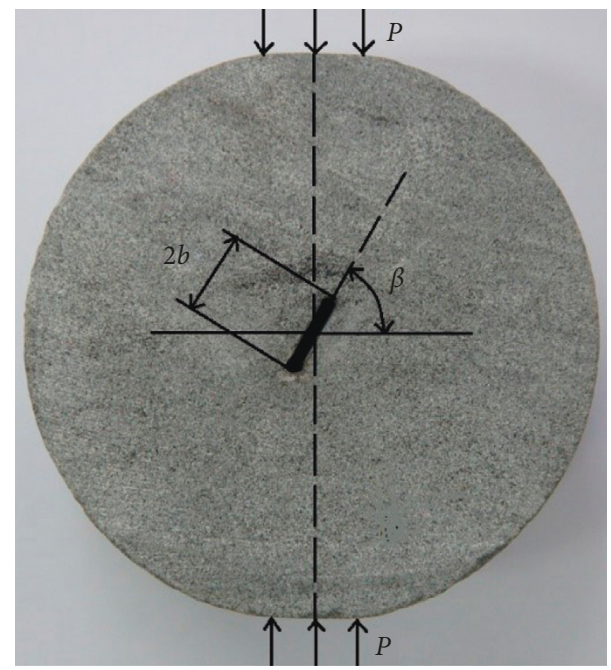

Figure 4: Schematic view of the fine sandstone CSCFBD specimen.

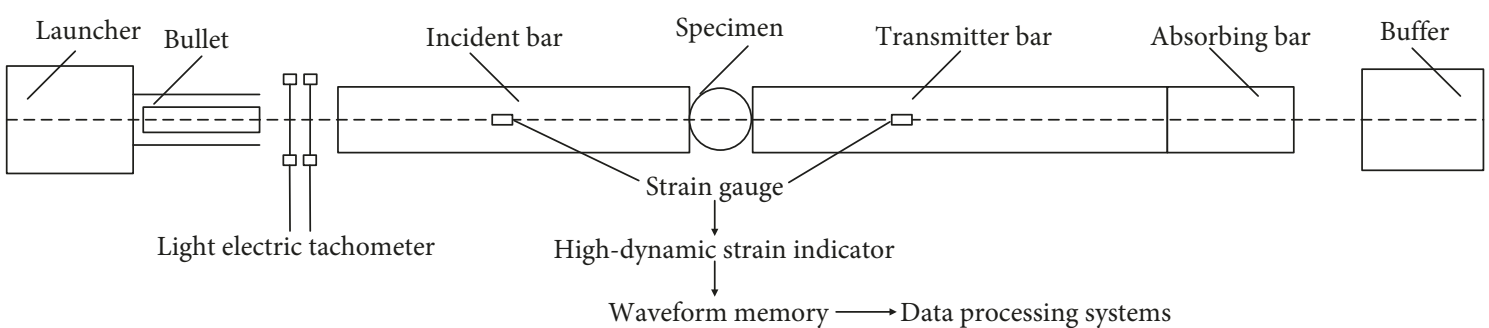

Figure 5: Schematic of the split Hopkinson pressure bar (SHPB) device.

to the center angle $2 \alpha$ to meet $20^{\circ} \leq 2 \alpha \leq 30^{\circ}$. Figure 6 shows the flattened $\mathrm{BD}$ specimen under radial loading. Before the installation of the specimens, a layer of Vaseline is evenly applied to the contact between the end of the specimen and the end of the compression bar, and the specimens need to be tightened between the incident bar and the transmitter bar. During SHPB tests, the brittle materials may fail before stress uniformly is achieved within the specimens. Modification of the incident pulse to closely match the elastic response is required. The pulse shaping technique has been widely applied in SHPB testing of engineering materials, and it is especially used for investigating the dynamic response of brittle materials. In this paper, we used a pulse shaping technique, a thin copper disk $(12 \mathrm{~mm}$-diameter and $1 \mathrm{~mm}$ thickness) which was placed on the impact side of the incident bar. The pulse shape can attenuate high-frequency oscillations of the incident stress wave to improve the stress wave shape. Pulse shaping technique allows for controlling the damage of brittle materials $[29,30]$.

\section{Experimental Results}

3.1. Impact Time Analysis of CSCFBD Specimens. During testing, the air pressure in the gas gun chamber was kept constant $0.1 \mathrm{MPa}$, equal to the impact velocity $3.76 \mathrm{~m} / \mathrm{s}$, and the bullet must be brought back to its original position before the next loading. The times of impacts were recorded for each specimen until final failure. As shown in Figure 7, to reach the final crack propagation paths forms, 6 times

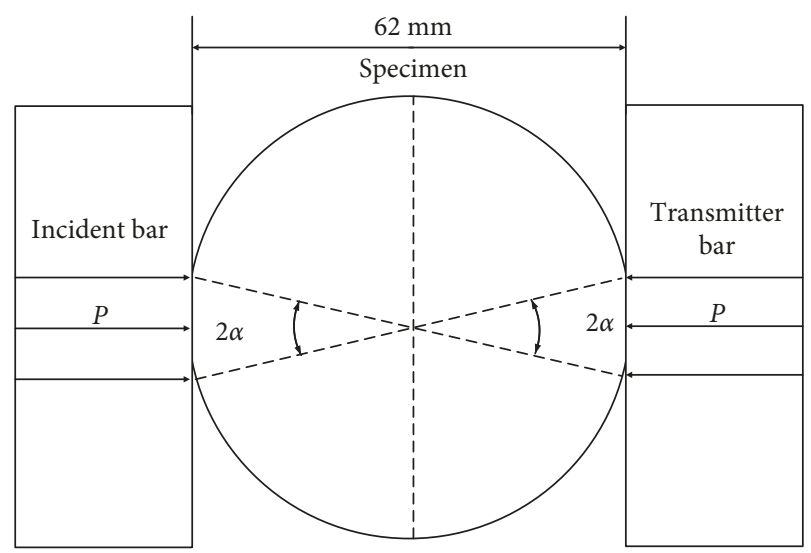

FIGURE 6: Flattened BD specimen under radial impact loading.

impact loading are needed when $\beta=0^{\circ}$ and the impact times are $3,4,6,4,2$, and 2 when $\beta=15^{\circ}, 30^{\circ}, 45^{\circ}, 60^{\circ}, 75^{\circ}$, and $90^{\circ}$ respectively. It is obvious that the impact times in final failure are related to the pre-existing inclination angles. Because pre-cracks can make the specimen strength to reduce, so when $\beta=15^{\circ}, 75^{\circ}$, and $90^{\circ}$, the impact times are usually less than the cases of $\beta=0^{\circ}, 30^{\circ}, 45^{\circ}$, and $90^{\circ}$.

3.2. Dynamic Crack Propagation Paths and Directions of CSCFBD Specimens. In this paper, we investigated the dynamic crack propagation paths and directions in CSCFBD specimens. In Figure 8, the crack propagation paths in 


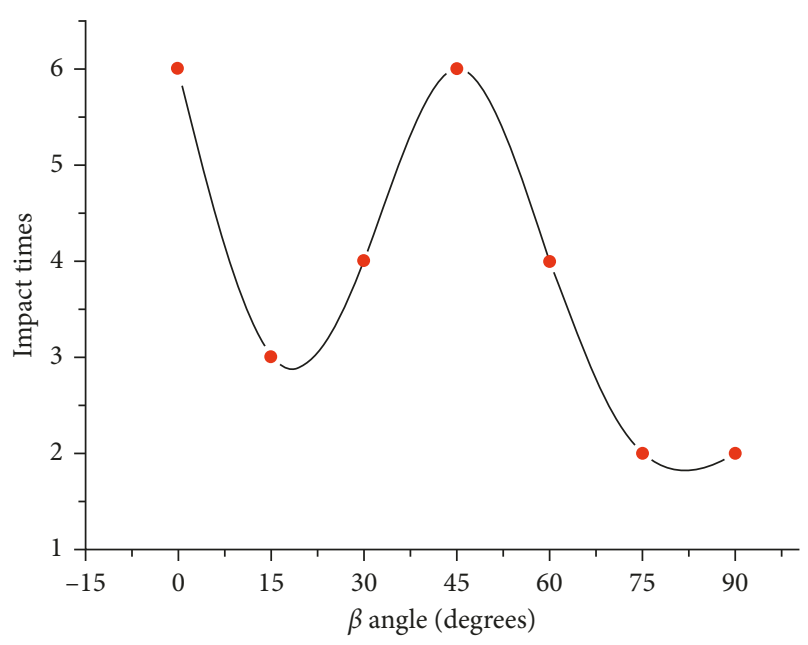

FIGURE 7: Impact times in final crack propagation path forms when $\beta=0^{\circ}, 15^{\circ}, 30^{\circ}, 45^{\circ}, 60^{\circ}, 75^{\circ}$, and $90^{\circ}$.

CSCFBD specimens with different inclination angles are indicated, and for all figures, the upper plane edges of the specimens are contacted with the incident bar. As shown in Figures $8(\mathrm{~b})-8(\mathrm{~g})$, cracks initiated from the tips of pre-cracks and approximately propagated towards the direction of the maximum stress. It should be noted that, in Figure $8(\mathrm{a})$, there is a crack initiated from the middle portion of the precrack when $\beta=0^{\circ}$.

Figure 8 (a) shows that five crack propagation paths appeared: two cracks started from the pre-existing crack's left-end tip and propagated to the specimen's lower plane edge; two cracks started from the pre-existing crack's rightend tip; the rest one crack propagated to the upper and lower plane edges. However, because of the high values of crack orientation with respect to the loading direction, there is one crack which did not propagate from the tip of the pre-crack. In Figures $8(\mathrm{c})$ and $8(\mathrm{~d}), \beta=30^{\circ}, 45^{\circ}$ respectively, five crack propagation paths appeared. Figure 8 (c) shows that there are two cracks that started from the pre-crack upper tip and propagated to the upper plane edge, two cracks started from the pre-crack lower tip and propagated to the lower plane edge, and the rest one crack started from the pre-crack upper tip and propagated to the lower plane edge. While in Figure $8(\mathrm{~d})$, there is one crack that started from the pre-crack lower tip and propagated to the upper plane edge. In Figures $8(\mathrm{~b}), 8(\mathrm{e})$, and $8(\mathrm{f}), \beta=15^{\circ}, 60^{\circ}$, and $75^{\circ}$, respectively, four main crack propagation paths appeared, and two of them started from the pre-crack upper tip and propagated to the upper plane edge. The other two started from the precrack lower tip and propagated to the lower plane edge. In Figure 8(b), an intermittent crack appeared, starting from the pre-crack lower tip, and has a downward trend to the lower plane edge. Figure 8(e) shows that the scatter of the four cracks presents regular symmetrical characteristic. As shown in Figure $8(\mathrm{~g}), \beta=90^{\circ}$, and the upper pre-crack tip propagated two crack propagation paths to the upper plane edge and one to the lower plane edge.

From Figures $8(\mathrm{a})-8(\mathrm{~g})$, it can be clearly seen that the final dynamic crack propagation paths and fracture patterns under impact loading are obviously different compared to those under static or quasi-static loading (e.g., Figure 9 [4]). In many studies, there is only one fracture that propagates from each tip of $\mathrm{BD}$ specimens under static or quasi-static loading. But under impact loading in the SHPB test, due to fractures with high strain rate, there are multiple crack propagation paths. The results also show the pre-existing inclination angles affect the multiple crack propagation paths and directions initiated from tips of the pre-cracks under cyclic dynamic loading.

\section{Discussion}

The crack propagation patterns were obtained in previous investigations of brittle materials with pre-cracks as shown in Figure $10[1,2]$. From the experimental results above, two types of cracks were observed: wing cracks and secondary cracks. Usually, the wing cracks are tensile cracks and the secondary cracks are shear cracks (oblique shear cracks and coplanar or quasi-coplanar shear). Table 2 summarizes crack types initiated from the pre-cracks in CSCFBD specimens under cyclic impact loading. Most of the tensile cracks and shear cracks initiated from the tips of pre-cracks at an angle and then propagate to the parallel to the compressive direction. Shear cracks' initiation patterns depend on the inclination angles of the pre-cracks. Under impact loading, shear cracks caused the failure of the tested specimens mostly.

Fracture and failure of pre-cracked CSCFBD specimens under cyclic impact loading involve tensile and shear crack types. Because of pre-cracks, the fracture patterns and failure modes are much more complex than those of intact brittle materials. Note that all the CSCFBD specimens present multiply crack propagation paths. But the geometries of pre-cracks appear to play limited effects on the crack type of CSCFBD specimens under cyclic impact loading.

In this paper, we studied the dynamic crack propagation and fracture patterns in pre-cracked CSCFBD specimens from deep underground strata under cyclic impact loading. The dynamic crack propagation paths and directions are obviously different from those under static or quasi-static loading in the previous studies, and the experimental results present some regular symmetrical characteristics. The dynamic crack propagation paths and propagation directions are not only determined by material related but also dependent on the geometries of the pre-cracks. However, the geometries of pre-cracks appear to play limited effects on the final dynamic fracture patterns and failure modes of CSCFBD specimens under cyclic impact loading. Further research may be a focus on the dynamic crack propagation mechanism of brittle materials studied by experimental and numerical simulation comprehensively. Various numerical simulation methods, e.g., finite element method (FEM), extended finite element method (XFEM), finite differential method (FDM), and different criteria, e.g., strain energy density (SED) criterion, cohesive zone model (CZM) [50] for theoretical analysis, have been developed to investigate 


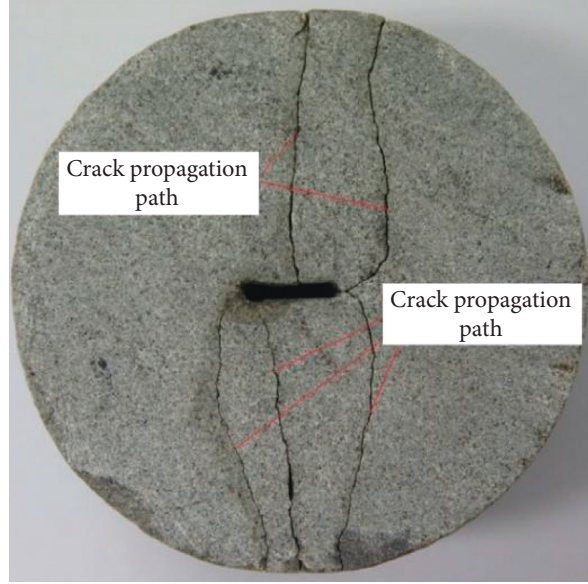

(a)

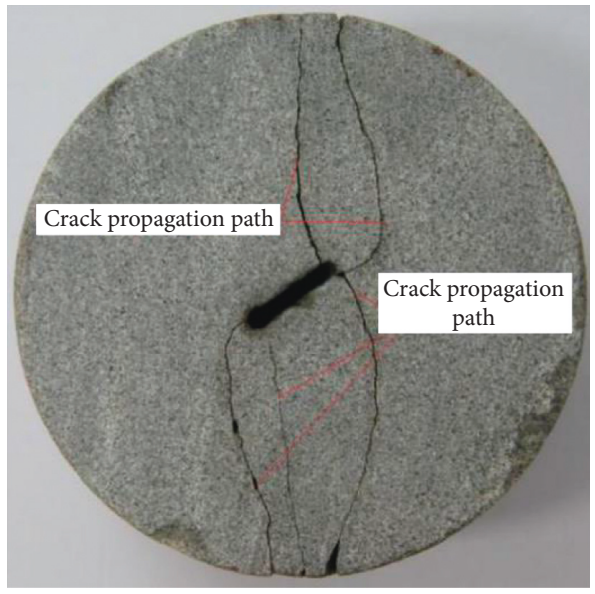

(c)

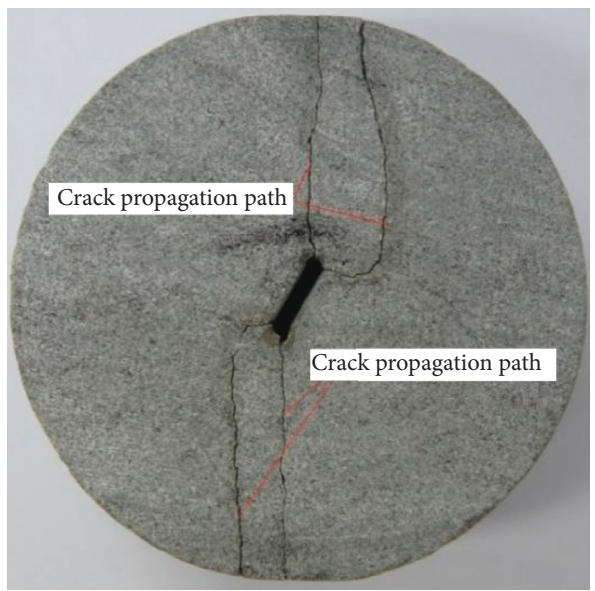

(e)

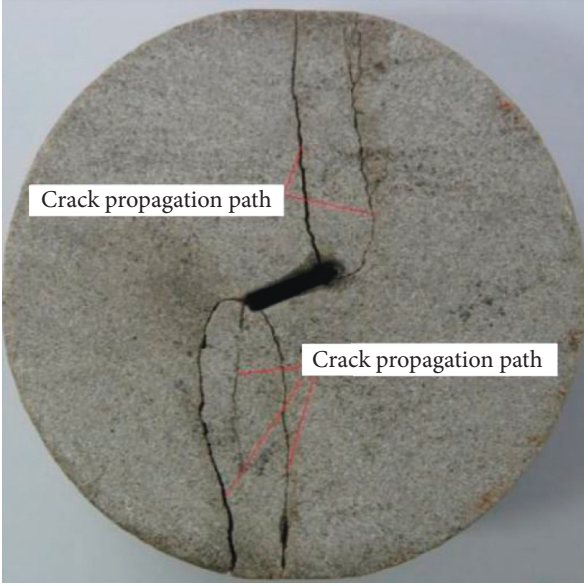

(b)

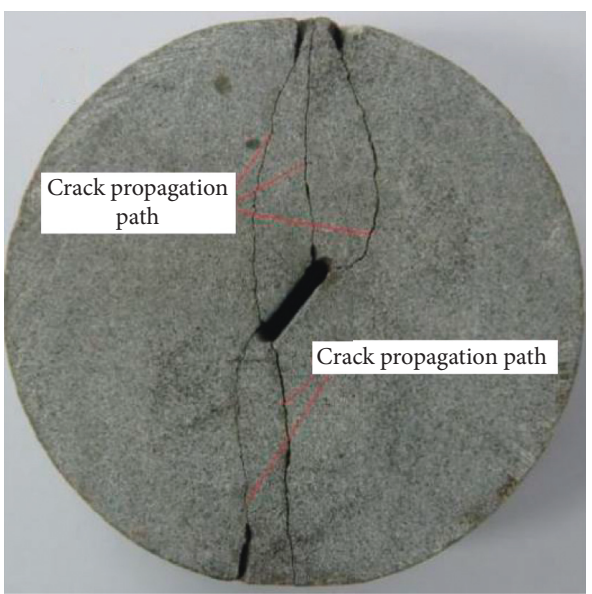

(d)

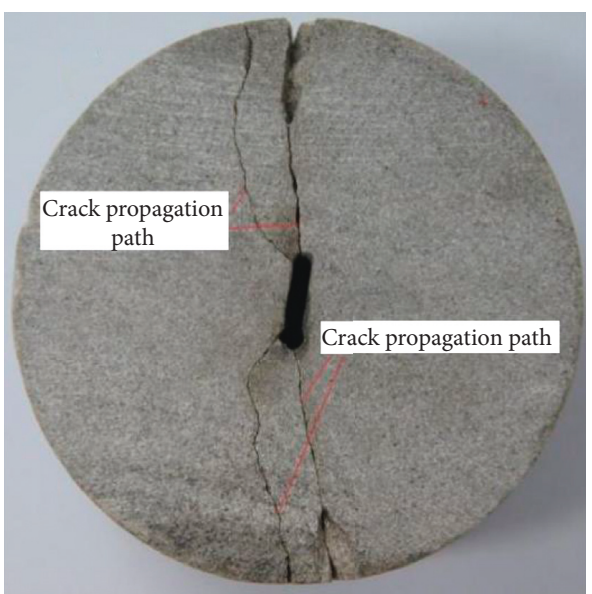

(f)

Figure 8: Continued. 


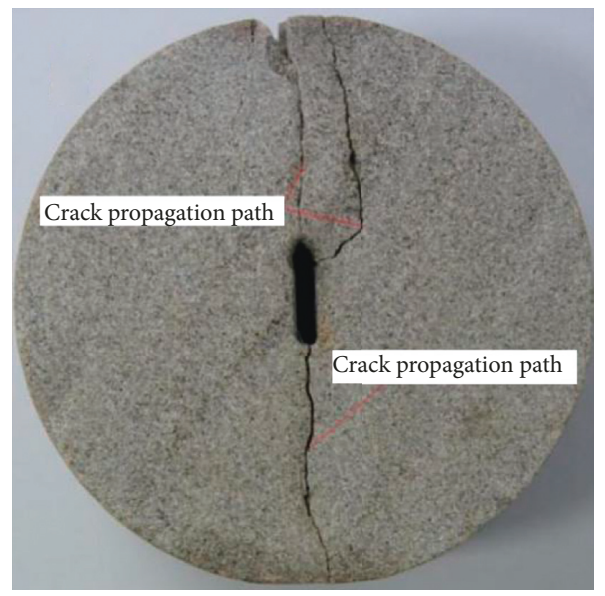

(g)

FiguRE 8: Crack propagation paths in fine sandstone CSCFBD specimens with different inclination angles of pre-cracks: (a) $\beta=0$; (b) $\beta=15^{\circ}$; (c) $\beta=30^{\circ}$; (d) $\beta=45^{\circ}$; (e) $\beta=60^{\circ}$; (f) $\beta=75^{\circ}$; (g) $\beta=90^{\circ}$.

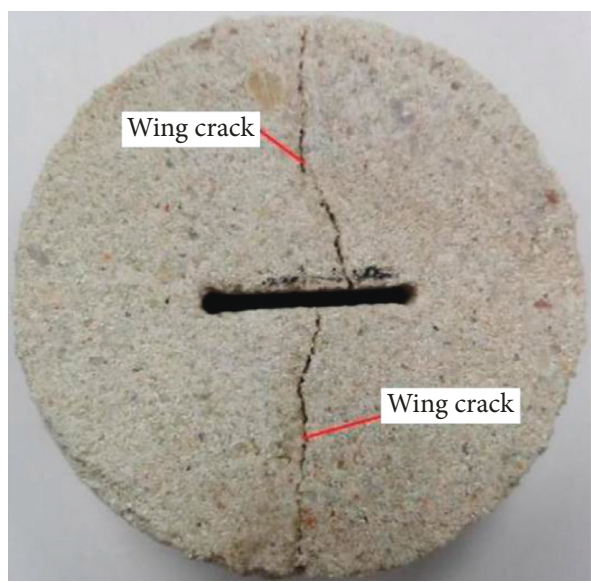

(a)

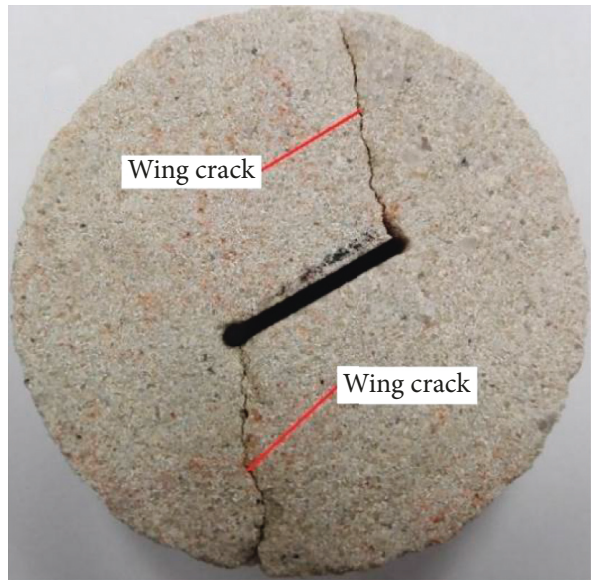

(c)

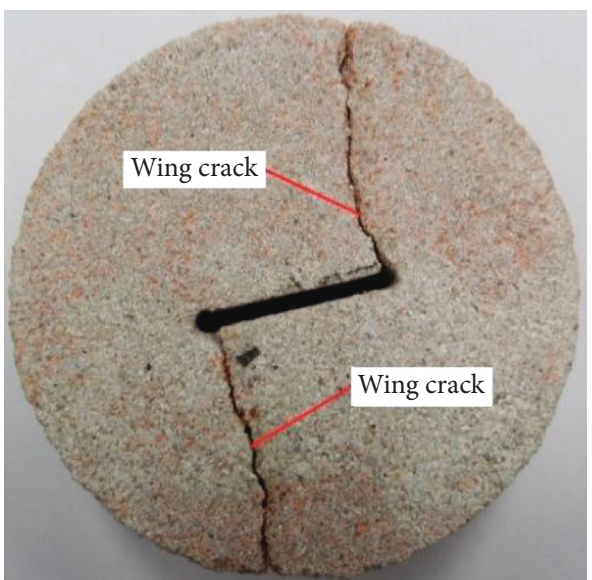

(b)

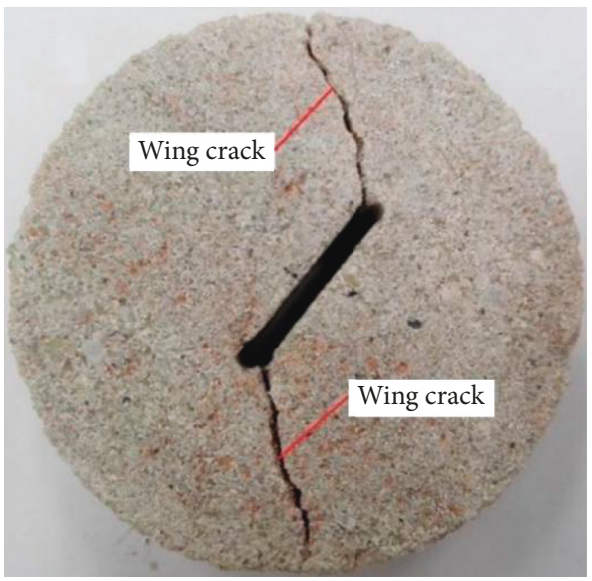

(d)

Figure 9: Continued. 


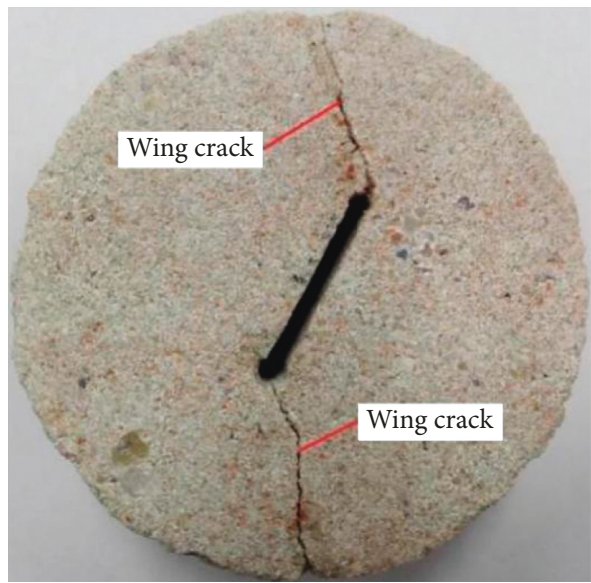

(e)

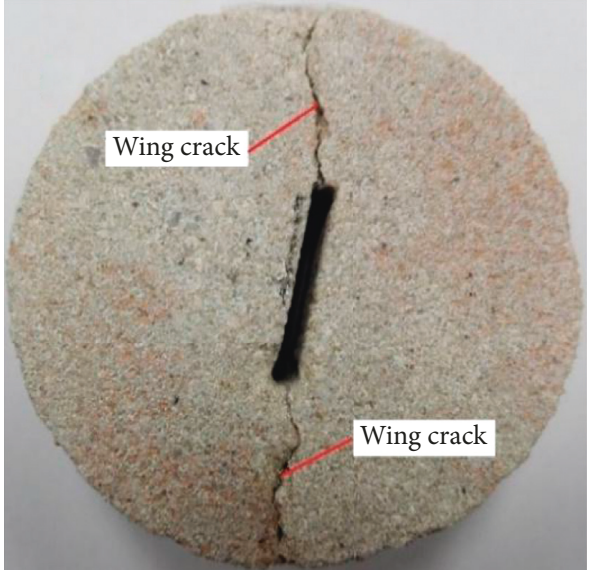

(f)

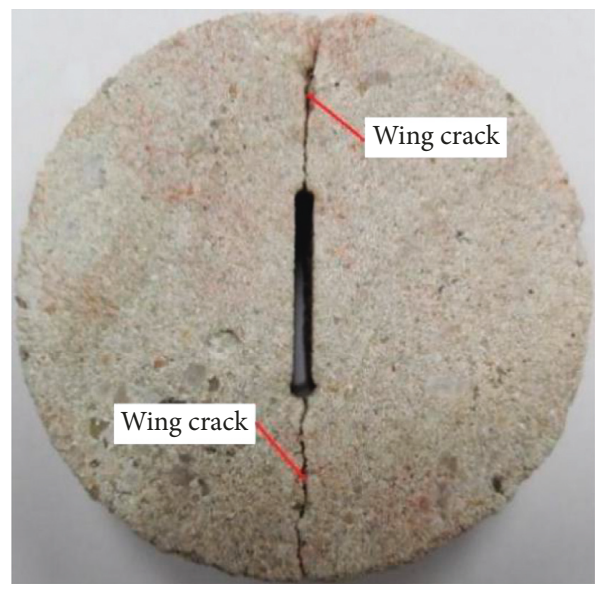

(g)

FIGURE 9: Experimental results of crack propagation paths in tested specimens with different inclination angles of pre-cracks: (a) $\beta=0$; (b) $\beta=15^{\circ}$; (c) $\beta=30^{\circ}$; (d) $\beta=45^{\circ}$; (e) $\beta=60^{\circ}$; (f) $\beta=75^{\circ}$; (g) $\beta=90^{\circ}$ [4].
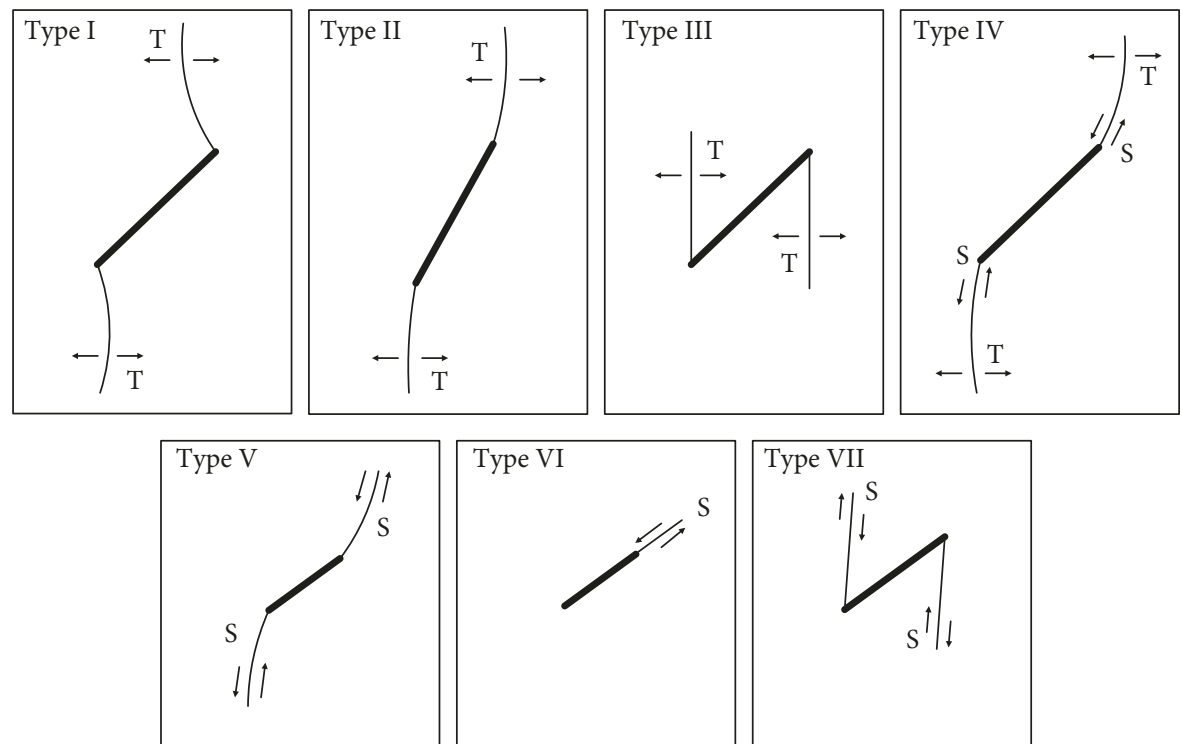

FIGURE 10: Various crack types initiated from the pre-cracks identified in the present studies (Tand S denote tensile and shear cracks).Type I: tensile crack; Type II: tensile crack; Type III: tensile crack; Type IV: mixed tensile-shear crack; Type V: shear crack; Type VI: shear crack (coplanar or quasi-coplanar shear crack); Type VII: shear crack (oblique shear crack) [1, 2]. 
TABLE 2: Types of cracks initiated from pre-cracked CSCFBD specimens under cyclic impact loading.

\begin{tabular}{lccccc}
\hline $\begin{array}{l}\text { Tested CSCFBD } \\
\text { specimen no. }\end{array}$ & Type I tensile & Type II tensile & Type III tensile & Type IV tensile-shear & Type V shear \\
\hline$\beta=0^{\circ}$ & $\sqrt{ }$ & $\sqrt{ }$ & $\sqrt{ }$ & $\sqrt{ }$ & \\
$\beta=15^{\circ}$ & $\sqrt{ }$ & $\sqrt{ }$ & & $\sqrt{ }$ & $\sqrt{ }$ \\
$\beta=30^{\circ}$ & $\sqrt{ }$ & $\sqrt{ }$ & $\sqrt{ }$ & $\sqrt{ }$ & $\sqrt{ }$ \\
$\beta=45^{\circ}$ & $\sqrt{ }$ & $\sqrt{ }$ & & $\sqrt{ }$ & $\sqrt{ }$ \\
$\beta=60^{\circ}$ & $\sqrt{ }$ & & $\sqrt{ }$ & $\sqrt{ }$ & \\
$\beta=75^{\circ}$ & & $\sqrt{ }$ & $\sqrt{ }$ & $\sqrt{ }$ & \\
$\beta=90^{\circ}$ & $\sqrt{ }$ & & $\sqrt{ }$ & Type VII shear \\
\hline
\end{tabular}

crack propagation, fracture patterns, and failure modes in brittle materials but have not shown satisfactory effectiveness in modeling dynamic damage evolution and crack propagation [51-53]. Using mesh-free particle methods to numerically study dynamic crack propagation may be an effective way. Especially in peridynamics, cracks are part of the solution, not part of the problem [54]. Therefore, using peridynamics to simulate dynamic multiple crack propagation and fracture patterns in brittle materials under impact or cyclic impact loading would be very meaningful which we plan for in the future.

\section{Conclusions}

In this paper, we provide experimental results of dynamic fracture tests carried out on fine sandstone CSCFBD specimens under cyclic impact loading by the $\Phi 74 \mathrm{~mm}-$ diameter SHPB device. Dynamic crack propagation and fracture mechanism are rather complicated processes. From the results presented and analyzed above, the following conclusions could be drawn:

(1) Compared to static or quasi-static loading, the dynamic crack propagation and fracture behavior are much more complex, and it presents multiple crack propagation paths and directions in dynamic fracture.

(2) Both tensile and shear cracks were observed, most of them mainly initiated from tips of the pre-cracks and propagated in a stable manner. According to the different geometries of pre-cracks, the tested CSCFBD specimens experienced tensile or shear crack propagation failure.

(3) The natural or artificial pre-existing defects can change the crack propagation paths, especially directions under impact loading compared to static or quasi-static loading. However, the geometries of pre-cracks appear to play limited effects on cracks type of CSCFBD specimens under cyclic impact loading.

(4) Dynamic crack propagation and fracture mechanism are rather complicated processes. This study revealed multiple dynamic crack propagation behavior that had not been observed previously. Numerical simulation is further needed to be summarized and explored which we plan for in the future.

\section{Data Availability}

The data used to support the findings of this study are available from the corresponding author upon request.

\section{Conflicts of Interest}

The authors declare that they have no conflicts of interest.

\section{Acknowledgments}

The research described in this paper was financially supported by the National Key Technologies Research \& Development Program (nos. 2018YFC0406703 and 2017YFC1502600), the National Natural Science Foundation of China (nos. 11672101 and 11372099), the Postgraduate Research \& Practice Innovation Program of Jiangsu Province (no. KYLX16_0700), and the Fundamental Research Funds for the Central Universities (no. 2016B45214).

\section{References}

[1] L. N. Y. Wong and H. H. Einstein, "Crack coalescence in molded gypsum and Carrara marble: part 1-macroscopic observations and interpretation," Rock Mechanics and Rock Engineering, vol. 42, no. 3, pp. 475-511, 2009.

[2] L. N. Y. Wong and H. H. Einstein, "Crack coalescence in molded gypsum and carrara marble: part 2-microscopic observations and interpretation," Rock Mechanics and Rock Engineering, vol. 42, no. 3, pp. 513-545, 2009.

[3] H. Cheng, X. Zhou, J. Zhu, and Q. Qian, "The effects of crack openings on crack initiation, propagation and coalescence behavior in rock-like materials under uniaxial compression," Rock Mechanics and Rock Engineering, vol. 49, no. 9, pp. 3481-3494, 2016.

[4] S. J. Zhao, Q. Zhang, and L. M. Liu, "Crack initiation, propagation and coalescence experiments in sandstone Brazilian disks containing pre-existing flaws," Advances in Civil Engineering, vol. 2019, Article ID 9816067, 11 pages, 2019.

[5] A. Bobet and H. H. Einstein, "Fracture coalescence in rocktype materials under uniaxial and biaxial compression," International Journal of Rock Mechanics and Mining Sciences, vol. 35, no. 7, pp. 863-888, 1998.

[6] E. Hoek and C. D. Martin, "Fracture initiation and propagation in intact rock-a review," Journal of Rock Mechanics and Geotechnical Engineering, vol. 6, no. 4, pp. 287-300, 2014.

[7] X. Zhuang, J. Chun, and H. Zhu, "A comparative study on unfilled and filled crack propagation for rock-like brittle material," Theoretical and Applied Fracture Mechanics, vol. 72, pp. 110-120, 2014. 
[8] P. Cao, T. Liu, C. Pu, and H. Lin, "Crack propagation and coalescence of brittle rock-like specimens with pre-existing cracks in compression," Engineering Geology, vol. 187, pp. 113-121, 2015.

[9] Q. B. Zhang and J. Zhao, "Determination of mechanical properties and full-field strain measurements of rock material under dynamic loads," International Journal of Rock Mechanics and Mining Sciences, vol. 60, pp. 423-439, 2013.

[10] M. D. Kuruppu, Y. Obara, M. R. Ayatollahi, K. P. Chong, and T. Funatsu, "ISRM-suggested method for determining the mode I static fracture toughness using semi-circular bend specimen," Rock Mechanics and Rock Engineering, vol. 47, no. 1, pp. 267-274, 2014.

[11] M. D. Kuruppu, "Fracture toughness measurement using chevron notched semi-circular bend specimen," International Journal of Fracture, vol. 86, no. 4, pp. L33-L38, 1997.

[12] A. M. Shiryaev and A. M. Kotkis, "Methods for determining fracture toughness of brittle porous materials," Industrial Laboratory, vol. 48, no. 9, pp. 917-918, 1983.

[13] M. Thiercelin and J. C. Roegiers, "Fracture toughness determination with the modified ring test," in Proceedings of the International Symposium on Engineering in Complex Rock Formations, pp. 1-8, Beijing, China, November 1986.

[14] G. R. Irwin, "Analysis of stress and strains near the end of a crack traversing a plate," Journal of Applied Mechanics, vol. 24, no. 3, pp. 361-364, 1957.

[15] J. B. Walsh, "The effect of cracks on the compressibility of rock," Journal of Geophysical Research, vol. 70, no. 2, pp. 381-389, 1965.

[16] E. Hoek and Z. T. Bieniawski, "Brittle fracture propagation in rock under compression," International Journal of Fracture Mechanics, vol. 1, no. 3, pp. 137-155, 1965.

[17] S. Q. Yang, Y. H. Dai, L. J. Han, and Z. Q. Jin, "Experimental study on mechanical behavior of brittle marble samples containing different flaws under uniaxial compression," Engineering Fracture Mechanics, vol. 76, no. 12, pp. 1833-1845, 2009.

[18] C. H. Park and A. Bobet, "Crack coalescence in specimens with open and closed flaws: a comparison," International Journal of Rock Mechanics and Mining Sciences, vol. 46, no. 5, pp. 819-829, 2009.

[19] R. P. Janeiro and H. H. Einstein, "Experimental study of the cracking behavior of specimens containing inclusions (under uniaxial compression)," International Journal of Fracture, vol. 164, no. 1, pp. 83-102, 2010.

[20] S. Q. Yang, "Crack coalescence behavior of brittle sandstone samples containing two coplanar fissures in the process of deformation failure," Engineering Fracture Mechanics, vol. 78, no. 17, pp. 3059-3081, 2011.

[21] M. R. M. Aliha, M. Sistaninia, D. J. Smith, M. J. Pavier, and M. R. Ayatollahi, "Geometry effects and statistical analysis of mode I fracture in guiting limestone," International Journal of Rock Mechanics and Mining Sciences, vol. 51, pp. 128-135, 2012.

[22] M. R. Ayatollahi and M. R. M. Aliha, "On the use of Brazilian disc specimen for calculating mixed mode I-II fracture toughness of rock materials," Engineering Fracture Mechanics, vol. 75, no. 16, pp. 4631-4641, 2008.

[23] A. Ghazvinian, H. R. Nejati, V. Sarfarazi, and M. R. Hadei, "Mixed mode crack propagation in low brittle rock-like materials," Arabian Journal of Geosciences, vol. 6, no. 11, pp. 4435-4444, 2013.
[24] N. A. Al-Shayea, "Crack propagation trajectories for rocks under mixed mode I-II fracture," Engineering Geology, vol. 81, no. 1, pp. 84-97, 2005.

[25] H. Haeri, K. Shahriar, M. F. Marji, and P. Moarefvand, "Experimental and numerical study of crack propagation and coalescence in pre-cracked rock-like disks," International Journal of Rock Mechanics and Mining Sciences, vol. 67, no. 6, pp. 20-28, 2014.

[26] H. Haeri, A. Khaloo, and M. F. Marji, "Fracture analyses of different pre-holed concrete specimens under compression," Acta Mechanica Sinica, vol. 31, no. 6, pp. 855-870, 2015.

[27] H. Haeri, V. Sarfarazi, and A. Hedayat, "Suggesting a new testing device for determination of tensile strength of concrete," Structural Engineering and Mechanics, vol. 60, no. 6, pp. 939-952, 2016.

[28] M. R. M. Aliha and A. Bahmani, "Rock fracture toughness study under mixed mode I/III loading," Rock Mechanics and Rock Engineering, vol. 50, no. 7, pp. 1739-1751, 2017.

[29] D. J. Frew, M. J. Forrestal, and W. W. Chen, "Pulse shaping techniques for testing brittle materials with a split Hopkinson pressure bar," Experimental Mechanics, vol. 42, no. 1, pp. 93-106, 2002.

[30] D. J. Frew, M. J. Forrestal, and W. Chen, "Pulse shaping techniques for testing elastic-plastic materials with a split Hopkinson pressure bar," Experimental Mechanics, vol. 45, no. 2, pp. 186-195, 2005.

[31] X. Li, T. Zhou, and D. Li, "Dynamic strength and fracturing behavior of single-flawed prismatic marble specimens under impact loading with a split-Hopkinson pressure bar," Rock Mechanics and Rock Engineering, vol. 50, no. 1, pp. 29-44, 2017.

[32] Q. Z. Wang, J. R. Yang, C. G. Zhang et al., "Sequential determination of dynamic initiation and propagation toughness of rock using an experimental-numerical-analytical method," Engineering Fracture Mechanics, vol. 141, pp. 78-94, 2015.

[33] F. Dai, S. Huang, K. Xia, and Z. Tan, "Some fundamental issues in dynamic compression and tension tests of rocks using split Hopkinson pressure bar," Rock Mechanics and Rock Engineering, vol. 43, no. 6, pp. 657-666, 2010.

[34] W. Li and J. Xu, "Mechanical properties of basalt fiber reinforced geopolymeric concrete under impact loading," Materials Science and Engineering: A, vol. 505, no. 1-2, pp. 178-186, 2009.

[35] Z. L. Wang, H. H. Zhu, and J. G. Wang, "Repeated-impact response of ultrashort steel fiber reinforced concrete," Experimental Techniques, vol. 37, no. 4, pp. 6-13, 2013.

[36] X. Chen, S. Wu, and J. Zhou, "Experimental and modeling study of dynamic mechanical properties of cement paste, mortar and concrete," Construction and Building Materials, vol. 47, pp. 419-430, 2013.

[37] X. D. Chen, L. M. Ge, J. K. Zhou, and S. X. Wu, "Dynamic Brazilian test of concrete using split Hopkinson pressure bar," Materials and Structures, vol. 50, no. 1, 2017.

[38] M. Zhang, H. J. Wu, Q. M. Li, and F. L. Huang, "Further investigation on the dynamic compressive strength enhancement of concrete-like materials based on split Hopkinson pressure bar tests-part I: experiments," International Journal of Impact Engineering, vol. 36, no. 12, pp. 1327-1334, 2009.

[39] W. Chen and G. Ravichandran, "Failure mode transition in ceramics under dynamic multiaxial compression," International Journal of Fracture, vol. 101, no. 1-2, pp. 141-159, 2000. 
[40] H. Wang and K. T. Ramesh, "Dynamic strength and fragmentation of hot-pressed silicon carbide under uniaxial compression," Acta Materialia, vol. 52, no. 2, pp. 355-367, 2004.

[41] T. Ficker, "Quasi-static compressive strength of cement-based materials," Cement and Concrete Research, vol. 41, no. 1, pp. 129-132, 2011.

[42] H. Hao and B. G. Tarasov, "Experimental study of dynamic material properties of clay brick and mortar at different strain rates," Australian Journal of Structural Engineering, vol. 8, no. 2, pp. 117-132, 2008.

[43] M. Wu, C. Qin, and C. Zhang, "High strain rate splitting tensile tests of concrete and numerical simulation by mesoscale particle elements," Journal of Materials in Civil Engineering, vol. 26, no. 1, pp. 71-82, 2014.

[44] J. Xiao, L. Li, L. Shen, and C. S. Poon, "Compressive behaviour of recycled aggregate concrete under impact loading," Cement and Concrete Research, vol. 71, pp. 46-55, 2015.

[45] W. Wu, W. Zhang, and G. Ma, "Mechanical properties of copper slag reinforced concrete under dynamic compression," Construction and Building Materials, vol. 24, no. 6, pp. 910917, 2010.

[46] H. Su and J. Xu, "Dynamic compressive behavior of ceramic fiber reinforced concrete under impact load," Construction and Building Materials, vol. 45, pp. 306-313, 2013.

[47] Y. Al-Salloum, T. Almusallam, S. M. Ibrahim, H. Abbas, and S. Alsayed, "Rate dependent behavior and modeling of concrete based on SHPB experiments," Cement and Concrete Composites, vol. 55, pp. 34-44, 2015.

[48] C. A. Ross, P. Y. Thompson, and J. W. Tedesco, "SplitHopkinson pressure-bar tests on concrete and mortar in tension and compression," ACI Materials Journal, vol. 86, no. 5, pp. 475-481, 1989.

[49] Q. Z. Wang, X. M. Jia, S. Q. Kou, Z. X. Zhang, and P.-A. Lindqvist, "The flattened Brazilian disc specimen used for testing elastic modulus, tensile strength and fracture toughness of brittle rocks: analytical and numerical results," International Journal of Rock Mechanics and Mining Sciences, vol. 41, no. 2, pp. 245-253, 2004.

[50] F. Berto and J. Gomez, "Notched plates in mixed mode loading (I+II): a review based on the local strain energy density and the cohesive zone model," Engineering Solid Mechanics, vol. 5, pp. 1-8, 2017.

[51] D. Huang, Q. Zhang, and P. Qiao, "Damage and progressive failure of concrete structures using non-local peridynamic modeling," Science China Technological Sciences, vol. 54, no. 3, pp. 591-596, 2011.

[52] D. Huang, Q. Zhang, P. Z. Qiao, and F. Shen, "A review on peridynamics (PD) method and its applications," Advances in Mechanics, vol. 40, no. 4, pp. 448-459, 2010.

[53] H. Haeri, K. Shahriar, M. F. Marji, and P. Moarefvand, "A coupled numerical-experimental study of the breakage process of brittle substances," Arabian Journal of Geosciences, vol. 8, no. 2, pp. 809-825, 2015.

[54] Y. D. Ha and F. Bobaru, "Studies of dynamic crack propagation and crack branching with peridynamics," International Journal of Fracture, vol. 162, no. 1-2, pp. 229-244, 2010. 


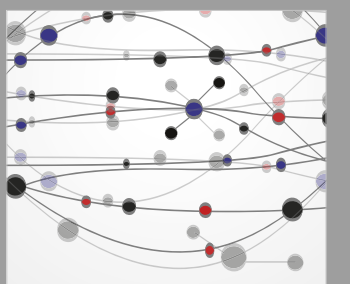

The Scientific World Journal
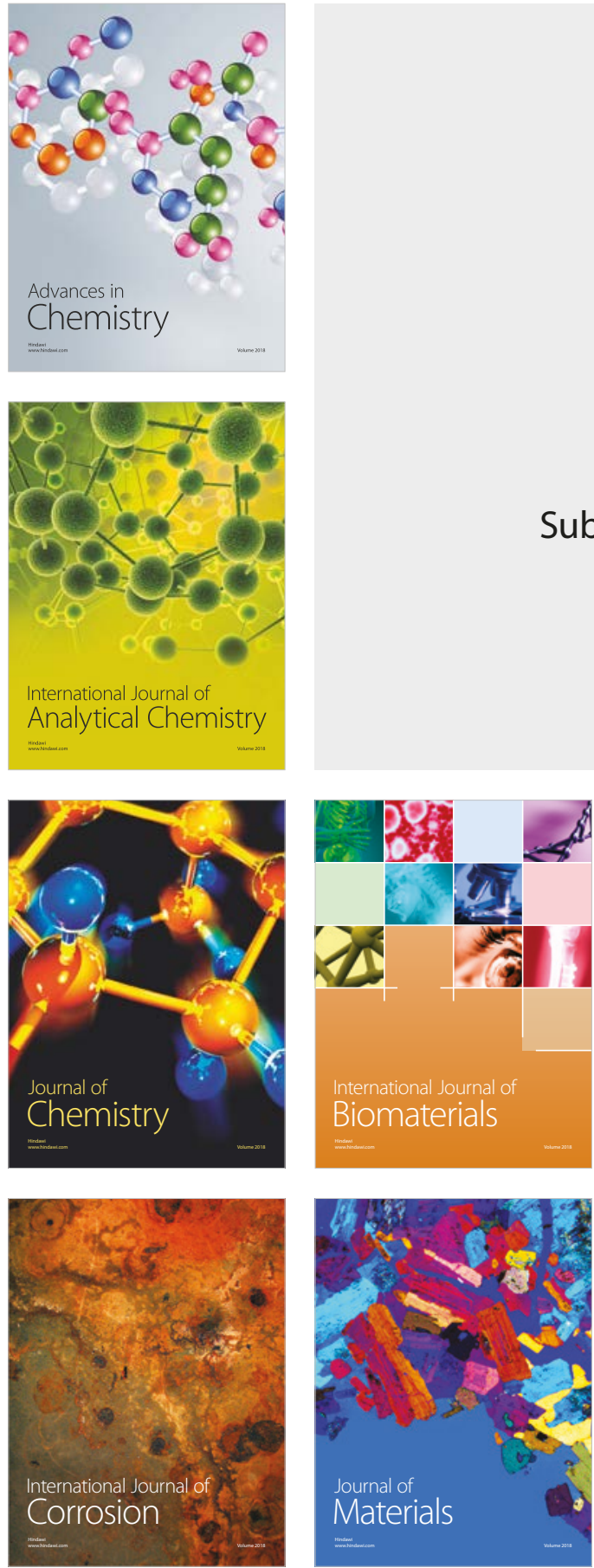

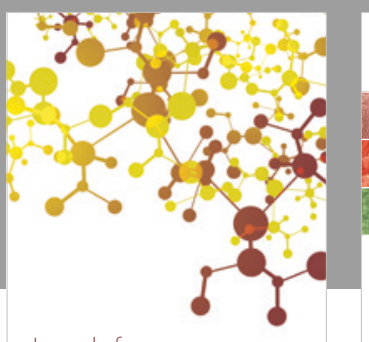

Journal of

Applied Chemistry
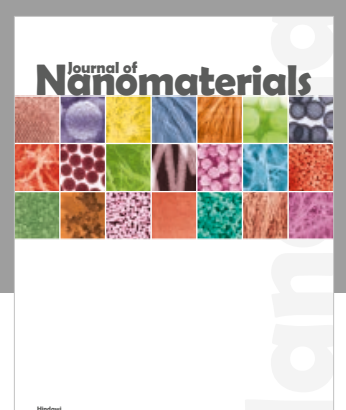

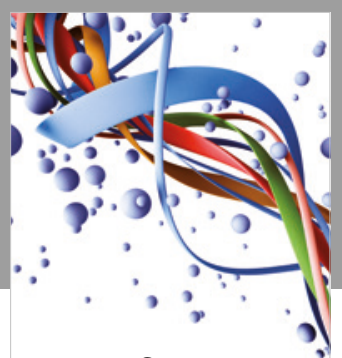

Scientifica

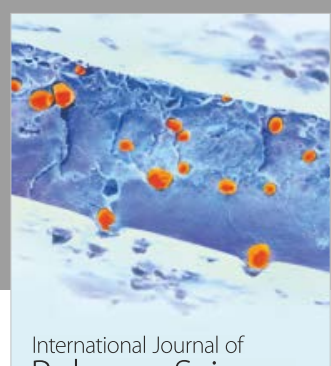

Polymer Science

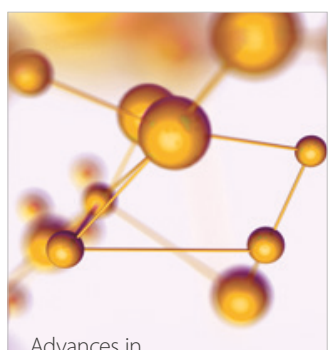

Physical Chemistry
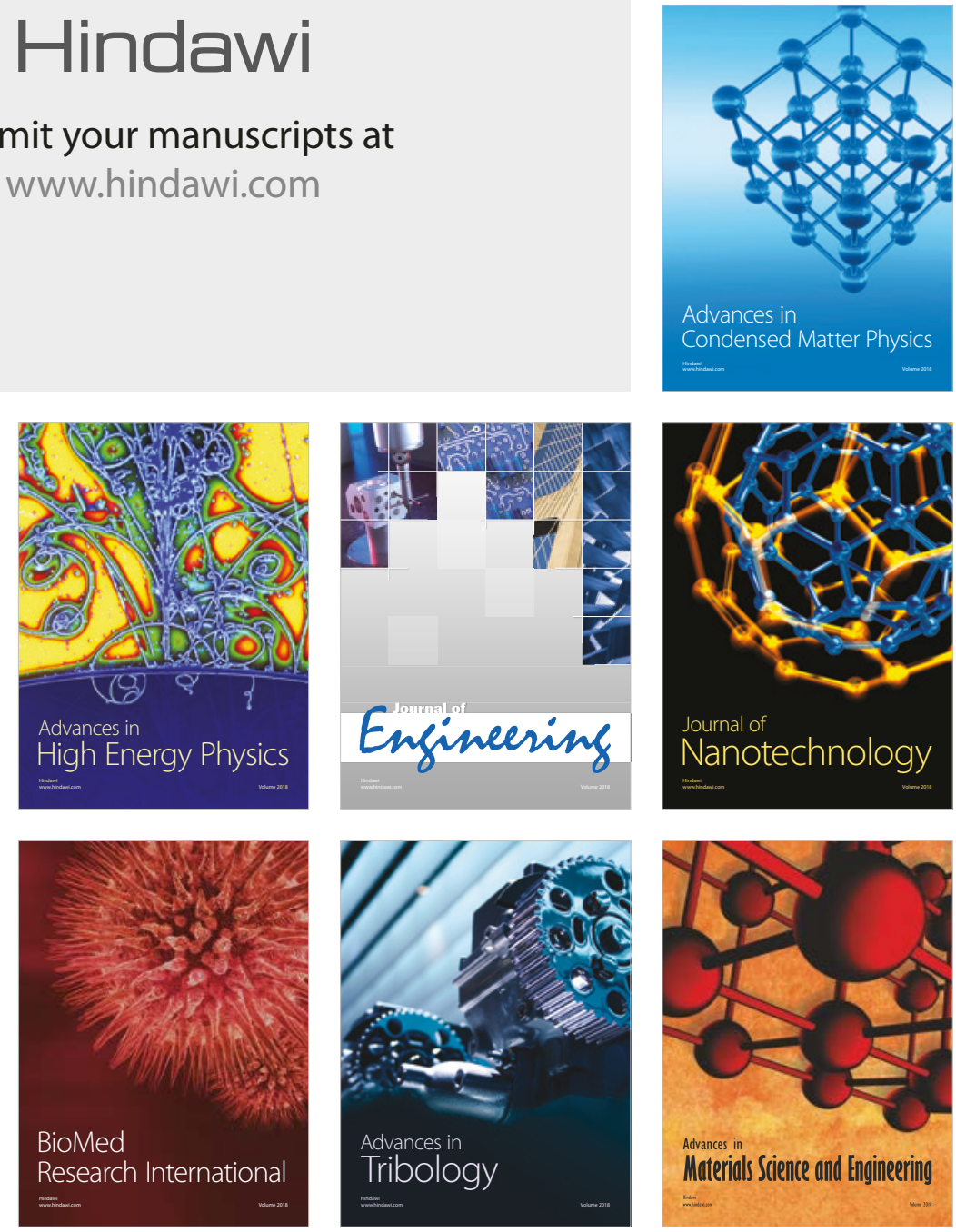